\title{
Traces photographiques, traces autobiographiques, sous la direction de Danièle Meaux et Jean-Bernard Vray
}

\section{Rosa Galli Pellegrini}

\section{(2) OpenEdition}

\section{Journals}

\section{Edizione digitale}

URL: https://journals.openedition.org/studifrancesi/38327

DOI: 10.4000/studifrancesi.38327

ISSN: 2421-5856

Editore

Rosenberg \& Sellier

\section{Edizione cartacea}

Data di pubblicazione: 15 décembre 2004

Paginazione: 651

ISSN: 0039-2944

\section{Notizia bibliografica digitale}

Rosa Galli Pellegrini, «Traces photographiques, traces autobiographiques, sous la direction de Danièle Meaux et Jean-Bernard Vray», Studi Francesi [Online], 144 (XLVIII | III) | 2004, online dal 30 novembre 2015, consultato il 08 mai 2021. URL: http://journals.openedition.org/studifrancesi/38327 ; DOI: https://doi.org/10.4000/studifrancesi.38327

Questo documento è stato generato automaticamente il 8 mai 2021.

\section{(c) $($ ) $\odot$ (8)}

Studi Francesi è distribuita con Licenza Creative Commons Attribuzione - Non commerciale - Non opere derivate 4.0 Internazionale. 


\title{
Traces photographiques, traces autobiographiques, sous la direction de Danièle Meaux et Jean-Bernard Vray
}

\author{
Rosa Galli Pellegrini
}

\section{NOTIZIA}

Traces photographiques, traces autobiographiques, sous la direction de Danièle MEAUX et Jean-Bernard VRAY, Saint-Etienne, publications de l'Université de Saint-Etienne, 2004, pp. 272-XVI.

1 Il volume raccoglie gli atti del Convegno omonimo, svoltosi nel maggio 2003 a SaintEtienne, sotto la supervisione degli stessi curatori. I contributi vertono sul presupposto critico che sottende al titolo, e cioè la consapevolezza che l'immagine fotografica, alla fine del secolo appena trascorso, interagisce con la scrittura e con altre arti rappresentative, nella veste di una traccia del passato che volentieri coinvolge il vissuto personale o collettivo. Di indagare in questa realtà, che rientra nella deriva dei generi che caratterizza l'arte in questo periodo nostro contemporaneo, si fanno carico gli autori, alcuni dei quali sono più prettamente interessati ai fotografi. Per quanto riguarda questa rubrica, mentre consigliamo vivamente anche la lettura di quei contributi, che aiutano ad illuminare ulteriormente il rapporto tra l'immagine e la scrittura, ci limiteremo a rendere conto dei saggi che studiano la relazione stretta tra l'immagine fotografica e l'(auto)biografia nell'opera degli scrittori.

2 Una prima parte del volume ( $\mathrm{La}$ Trace) è orientata piuttosto verso la teoria di questa problematica, anche se accoglie un'analisi del libro di Jean-Louis Baudry da parte di SERGE GAUBERT, Le Jeu de la carte, pp. 33-38. Nella seconda sezione (Images et mise en récit), due contributi vertono sull'attività di Sophie Calle, per quanto appaia difficile 
classificare questa scrittrice nella tradizione dell'autobiografia: infatti JEAN ARROUYE, Des Histoires vraies+dix. Photographie et autobiographie, pp. 65-71, e JEAN PAUL GUICHARD, Poker menteur: de la photographie comme preuve de l'existence de Sophie Calle, pp. 73-81, si interrogano, ognuno da un punto di vista diverso e basandosi su testi diversi, sull'autenticità del procedimento autobiografico nella scrittura di questa autrice. Se la terza parte ( Photographies et vies intimes), maggiormente centrata sulle esperienze dei fotografi, offre importanti suggestioni di riflessione e di aggancio critico metodologico anche per lo studioso della scrittura contemporanea, tuttavia è l'ultima sezione (Photographie et écriture autobiographique) che raccoglie i contributi riguardanti più specificamente la creazione letteraria.

Alain SChaffner, L'Image de soi dans le récit d'enfance, pp. 191-205, inizia la sezione con un'indagine sulla presenza e il significato della fotografia nella narrazione della propria infanzia da parte di alcuni autori, per arrivare alla affermazione che, fino agli anni 1970, la riflessione sull'immagine serve a "costituire» piuttosto che a «restituire» un'immagine de se'. I contributi successivi alternano le posizioni critiche focalizzandosi talora sul rapporto tra testo e immagine fotografica, come propone STEPHANE CHAUDIER, Barthes: la photographie ou l'ontologie précaire, 207-214, riguardo al senso dell'oggetto fotografico in Barthes, o anche AGNES CASTIGLIONE, Fenêtres sur chambres: les "Belles endormies» de Gérard Macé, pp. 215-228, sull'uso dell'immagine in un autore/fotografo quale Macé. Sull'altro versante del rapporto, cioè quello che intercorre tra la fotografia e il testo, si pongono i contributi restanti, come quello di AGES F AYET, La ph(auto)biographie ou la rencontre du sorcier et du démiurge dans «Le Labyrinthe du monde», pp. 229-238, la quale parte dall'immagine come creatrice di racconto, magia dell'apparecchio fotografico e magia della ricreazione (auto)biografica. CHRISTINE JERUSALEM, Les Mécaniques optiques de François Bon: l'écrivain en photographe, pp. 239-248, indaga su Mécanique di Bon, mostrando i passaggi che il testo delinea tra passato e presente con l'ausilio della fotografia, soffermandosi sul riferimento alla «meccanica» ritratta, come immagine portante della narrazione. Con il lavoro di PhiLIPPE ANTOINE, Voyages photobiographiques, pp. 249-259, si entra nei racconti di viaggio di Olivier Rolin e di Jean-Loup Troussard nella ex Unione Sovietica. L'ultimo contributo, di JEAN-BERNARD VRAY, Jean-Loup Trassard: la dormance et la trace, pp. 261-272, affronta la traccia fotografica in Dormance, quest'opera cumulativa di Trassard, mettendo in luce il sottile rapporto che si tesse, nel racconto, tra un passato archetipale e la traccia autobiografica dell'adolescenza del narratore. 